\title{
Acceptability of Sodium-Reduced Research Diets, Including the Dietary Approaches to Stop Hypertension Diet, among Adults with Prehypertension and Stage 1 Hypertension
}

\section{Citation}

Karanja, Njeri, Kristie J. Lancaster, William M. Vollmer, Pao-Hwa Lin, Marlene M. Most, Jamy D. Ard, Janis F. Swain, Frank M. Sacks, and Eva Obarzanek. 2007. “Acceptability of Sodium-Reduced Research Diets, Including the Dietary Approaches to Stop Hypertension Diet, Among Adults with Prehypertension and Stage 1 Hypertension." Journal of the American Dietetic Association 107 (9) (September): 1530-1538. doi:10.1016/j.jada.2007.06.013.

\section{Published Version}

doi:10.1016/j.jada.2007.06.013

\section{Permanent link}

http://nrs.harvard.edu/urn-3:HUL.InstRepos:30085348

\section{Terms of Use}

This article was downloaded from Harvard University's DASH repository, and is made available under the terms and conditions applicable to Other Posted Material, as set forth at http:// nrs.harvard.edu/urn-3:HUL.InstRepos:dash.current.terms-of-use\#LAA

\section{Share Your Story}

The Harvard community has made this article openly available.

Please share how this access benefits you. Submit a story.

\section{Accessibility}




\title{
Acceptability of Sodium-Reduced Research Diets, Including the Dietary Approaches to Stop Hypertension Diet, among Adults with Prehypertension and Stage 1 Hypertension
}

\author{
NJERI KARANJA, PhD[senior investigators] \\ Kaiser Permanente Center for Health Research, Portland \\ KRISTIE J. LANCASTER, PhD, RD[associate professor] \\ Department of Nutrition, Food Studies, and Public Health, New York University, New York \\ WILLIAM M. VOLLMER, PhD[senior investigators] \\ Kaiser Permanente Center for Health Research, Portland \\ PAO-HWA LIN, PhD[associate research professor] \\ Department of Medicine, Duke Hyptertension Center and the Sarah W. Stedman Center for \\ Nutritional Studies, Duke University Medical Center, Durham, NC
}

MARLENE M. MOST, PhD, RD, FADA[associate professor, research]

Pennington Biomedical Research Center, Baton Rouge, LA

JAMY D. ARD, MD[assistant professor]

Department of Nutrition Sciences, University of Alabama, Birmingham

JANIS F. SWAIN, MS, RD[bionutrition manager]

National Institutes of Health General Clinical Research Center, Brigham and Women's Hospital, Boston, MA

FRANK M. SACKS, MD[professor]

Department of Medicine, Brigham and Women's Hospital and Harvard Medical School, and Nutrition Department, Harvard School of Public Health, Boston, MA

EVA OBARZANEK, PhD, RD[research nutritionist]

National Heart, Lung, and Blood Institute, Bethesda, MD

\section{Abstract}

Objective-Examine the acceptability of sodium-reduced research diets.

Design-Randomized crossover trial of three sodium levels for 30 days each among participants randomly assigned to one of two dietary patterns.

Participants/setting-Three hundred fifty-four adults with prehypertension or stage 1 hypertension who were participants in the Dietary Approaches to Stop Hypertension (DASHSodium) outpatient feeding trial.

Intervention-Participants received their assigned diet (control or DASH, rich in fruits, vegetables, and low-fat dairy products), each at three levels of sodium (higher, intermediate, and lower) corresponding to $3,500,2,300$, and $1,200 \mathrm{mg} /$ day $(150,100$, and $50 \mathrm{mmol} / \mathrm{day})$ per 2,100 kcal. 
Main outcome measures-Nine-item questionnaire on liking and willingness to continue the assigned diet and its level of saltiness using a nine-point scale, ranging from one to nine.

Statistical analyses performed-Generalized estimating equations to test participant ratings as a function of sodium level and diet while adjusting for site, feeding cohort, carryover effects, and ratings during run-in.

Results-Overall, participants rated the saltiness of the intermediate level sodium as most acceptable (DASH group: 5.5 for intermediate vs 4.5 and 4.4 for higher and lower sodium; control group: 5.7 for intermediate vs 4.9 and 4.7 for higher and lower sodium) and rated liking and willing to continue the DASH diet more than the control diet by about one point (ratings range from 5.6 to 6.6 for DASH diet and 5.2 to 6.1 for control diet). Small race differences were observed in sodium and diet acceptability.

Conclusions-Both the intermediate and lower sodium levels of each diet are at least as acceptable as the higher sodium level in persons with or at risk for hypertension.

Reducing salt consumption lowers blood pressure both in short- and long-term studies $(1,2)$. The effect is greater among individuals with hypertension than those with normal blood pressure and among African Americans compared with whites (1-3). However, adherence to reduced sodium regimens has generally been low. Simple advice provided at health care settings, even when given at every visit, tends to have low effectiveness (4-7). With intensive counseling, only $20 \%$ to $40 \%$ of participants in sodium reduction trials reduce their sodium intakes to below the recommended upper limit of $2,300 \mathrm{mg} /$ day ( $100 \mathrm{mmol} /$ day $)(7-$ 10).

Researchers speculate that patients and research participants have difficulty adopting reduced-sodium diets because they are largely asymptomatic and may fail to perceive a benefit from a diet that they may consider too restrictive (4). Also, because individuals' preferred level of salt appears to be largely learned, salt levels that deviate the most from customary levels are likely to be less preferred (11) and reduced-sodium diets may have low palatability. The lack of sodium-reduced products in the food supply may also serve as a difficult barrier for individuals as well as counselors who try to promote reduced-sodium diets (12). Efforts to provide affordable, low-sodium foods would be aided by assessing the level of sodium that is acceptable to the consumer.

The importance of lower sodium intakes to reduce blood pressure was clearly shown by the Dietary Approaches to Stop Hypertension (DASH)-Sodium trial. The DASH-Sodium trial tested the effects on blood pressure of three levels of sodium (higher, intermediate, and lower, proportional to energy intake, and corresponding to 3,500,2,300, and 1,200 $\mathrm{mg} / \mathrm{day}$ $[150,100$, and $50 \mathrm{mmol} / \mathrm{d}]$ per $2,100 \mathrm{kcal}$ ) in 412 adults consuming two types of diets that were prepared in research kitchens (13-16). The two diets were a control diet, similar to what many Americans consume, and the DASH diet, rich in fruits, vegetables, and low-fat dairy products. The primary outcome of the trial was systolic blood pressure. The main results were previously published and showed that reducing sodium intake from higher to lower levels significantly decreased systolic and diastolic blood pressure by an average of $6.7 / 3.5 \mathrm{~mm} \mathrm{Hg}(P<0.0001)$ in those consuming the control diet and by $3.0 / 1.6 \mathrm{~mm} \mathrm{Hg}$ $(P<0.0001)$ for participants consuming the DASH diet (14). In each diet for similar reductions in sodium intake of about $50 \mathrm{mmol}$ per 2,100 kcal, systolic blood pressure was reduced twice as much at the lower sodium level compared with the intermediate level than at the intermediate level compared with the higher level. In addition, the DASH diet significantly lowered blood pressure at each of the three levels of sodium $(5.9 / 2.9 \mathrm{~mm} \mathrm{Hg}$ for higher, 5.0/2.5 $\mathrm{mm} \mathrm{Hg}$ for intermediate, and 2.2/1.0 $\mathrm{mm} \mathrm{Hg}$ for lower sodium) (14). 
The DASH-Sodium protocol included a self-administered questionnaire to assess participants' acceptability of the diets provided to them. Thus, data gathered from the trial provided the opportunity to examine acceptability of sodium levels as well as of the two diets among individuals with, or at risk for, hypertension and to evaluate if sodium and diet acceptability is influenced by demographic characteristics. This report presents the findings from the acceptability questionnaire from the DASH-Sodium trial.

\section{METHODS}

\section{DASH-Sodium Trial Design and Study Participants}

The DASH-Sodium trial was a multicenter, randomized, controlled trial that compared the effects on blood pressure of two diets at three sodium levels in adults with prehypertension or stage 1 hypertension. It was an out-patient feeding study, a design that promotes high adherence and control of dietary intake (17). Clinical centers located in Baltimore, MD; Baton Rouge, LA; Boston, MA; and Durham-Raleigh, NC; a coordinating center located in Portland, OR; and the National Heart, Lung and Blood Institute, in Bethesda, MD, collaborated on the study. The study design has been reported elsewhere $(13,14)$. Briefly, eligible participants were aged 22 years or older and had a systolic blood pressure of 120 to $159 \mathrm{~mm} \mathrm{Hg}$ and a diastolic blood pressure of 80 to $95 \mathrm{~mm} \mathrm{Hg}$. We excluded individuals taking blood pressure medications; those with a history of heart disease, renal insufficiency, hyperlipidemia, or diabetes mellitus; those receiving special diets; and those consuming more than 14 alcoholic drinks per week. Participants were recruited by the four clinical centers primarily from mass mailings.

The control diet, similar to what many Americans consume, had 3.6 servings per day of fruits and vegetables and 0.5 serving per day of dairy food at 2,100 kcal. In contrast, the DASH diet emphasizes fruits and vegetables (9.6 servings per day at 2,100 kcal) and low-fat dairy foods ( 2.7 servings per day at 2,100 kcal), which are the key defining DASH food groups. In addition, compared with the control diet, the DASH diet had higher amounts of whole grains ( 4.1 vs 0 servings per day), fish ( 0.5 vs 0.2 servings per day), and nuts and seeds ( 0.6 vs 0 serving per day), and fewer servings of fats ( 2.5 vs 5.8 servings per day), red meat ( 0.5 vs 1.5 servings per day), and sweets ( 0.5 vs 3.2 servings per day) per $2,100 \mathrm{kcal}$ (18).

After a 2-week run-in period during which prospective participants consumed the control diet containing 3,500 $\mathrm{mg} /$ day ( $150 \mathrm{mmol} /$ day) sodium per 2,100 kcal, 412 participants were randomly assigned to receive either the DASH diet (15), or to continue on the control diet for 90 days. All participants consumed their assigned diet at three levels of sodium for 30 days each in random order in a crossover design. The higher level approximated slightly lower-than-average American consumption, the intermediate level was similar to the upper limit of US recommendations $(19,20)$, and the lower level was close to sodium consumption in non-Westernized societies (21) and expected to lower blood pressure further (14).

All meals and snacks were prepared in research kitchens at the collaborating clinical centers. Participants consumed lunch or dinner onsite and took home their remaining meals and snacks for the next 24 hours or for the weekend. Similar foods were used for each sodium level; however, the lower sodium diet used unsalted or low-sodium varieties of several foods, and the higher sodium diet used the salted versions. To attain the higher sodium level, weighed table salt was added to entrees, recipes, or unsalted broth. Foods notably high in sodium due to processing or foods with salt topically added were either avoided (eg, pickles, salted pretzels, and salted nuts) or used in their low-salt or unsalted version throughout all sodium levels to reduce sodium variability within the product and reduce the potential for topically added salt being lost during distribution and handling. We monitored adherence by 
taking attendance of participants consuming their weekday onsite meals. Participants completed daily checklists, reviewed by study food and nutrition professionals, asking about their consumption of study meals, consumption of nonstudy foods, and non-consumption of study foods.

The institutional review boards of the five participating institutions approved the protocol, and all participants provided written informed consent.

\section{Assessment of Acceptability of Salt Levels and Diets}

As part of the DASH-Sodium trial protocol, we developed a brief semiquantitative questionnaire (Figure) to evaluate the acceptability of the experimental diets to which participants were assigned, as defined by their liking and willingness to continue after the study was completed. The questions evaluated the saltiness and acceptability of the saltiness of the diet, of the overall diet, and of eating two key components of the DASH diet (ie, the number of fruits and vegetables servings and the number of dairy servings). These two food groups would likely be the focus of a nutrition education program for teaching individuals to follow the DASH diet, in addition to promoting overall lower intake of total and saturated fat and sweets (22). The questions were scored using a nine-point scale ranging from one to nine, where the higher number indicated greater liking or willingness, except for the saltiness rating question, where the higher number indicated greater perception of the salt taste. A rating of four and five indicated a neutral response. Because salt acceptability may increase as individuals become acclimated to a different sodium level $(11,23)$, and one small study suggested that salt taste can change within 2 weeks (24), changes in salt acceptability between the beginning and end of 30 days of intake at a particular sodium level were also assessed.

All participants were requested to fill out the questionnaire at the end of the 2-week run-in period (baseline) during which they consumed the control diet at higher sodium and again at the beginning and end of each of the 30-day feeding periods. A total of 354 participants ( $86 \%$ of those randomized) completed the questionnaire on all seven occasions and were used for these analyses. The other 58 participants completed fewer than seven (average of 4.6) administrations of the questionnaire due to time constraints and logistic reasons.

\section{Statistical Methods}

To determine the influence of sodium level and the DASH diet on diet acceptability, we used generalized estimating equations (25) to fit linear models that examined end-of-sodium period acceptability ratings as a function of sodium level (lower, intermediate, and higher) and diet (DASH or control). Estimates of the DASH diet effect (vs the control diet), which are between-subject comparisons, were adjusted for differences between the two diet groups in acceptability ratings during the run-in period. We tested for interactions between DASH diet effects and sodium level. We also examined responses to the questionnaire by subgroups defined by sex, age ( 45 years or younger vs older than 45 years, which was the approximate median age; actual median was 47.0 years), obesity status (body mass index [BMI], calculated as $\mathrm{kg} / \mathrm{m}^{2}$; BMI $<30$ vs BMI $\geq 30$ ), hypertension status, and race (African American vs non-African American). We included interaction terms of these subgroups with indicators of diet and sodium level to test between-subgroup differences in acceptability ratings.

To assess if diet acceptability changed during the course of each sodium period, we fit an expanded model that included diet acceptability ratings taken at the beginning and at the end of each sodium period and, through suitable parameterization of the DASH, sodium, and 
time effects, estimated the change in acceptability between beginning and end-of-sodium period ratings for each diet-sodium combination.

All analyses were performed using SAS (version 8.2, 2001, SAS Institute Inc, Cary, NC) and included adjustment for site, feeding cohort, and carryover effects. An exchangeable covariance matrix was assumed for the repeated measurements for each person. $F$ tests were used to test statistical significance. The term significant refers to a $P$ value $<0.05$.

\section{RESULTS}

The demographic profile of the 354 participants who completed all seven diet acceptability questionnaires was similar to the 412 participants (14) who were enrolled in the trial (data not shown), resulting in an $86 \%$ response rate. Incomplete or nonrespondents $(\mathrm{n}=58)$ had similar demographic characteristics as complete respondents $(n=354)$ with respect to age, BMI, sex, race, and hypertension status (data not shown), but were less likely to have had some college education (70\% of incomplete or nonrespondents had some college education compared with $85 \%$ of complete respondents, $P<0.01)$. Participants assigned to the DASH $(\mathrm{n}=180)$ and control diets $(\mathrm{n}=174)$ had similar baseline characteristics. Women made up $61 \%$ of the DASH group and 55\% of the control group, and African Americans made up $56 \%$ of the DASH group and 59\% of the control group. Mean age was 47.8 years for the DASH group and 49.2 years for the control group, and mean BMI was 28.9 and 29.5, respectively. Forty-one percent of DASH participants and 39\% of control participants had hypertension, and at least some college education was attained by $89 \%$ of the DASH group and $81 \%$ of the control group.

Adherence was high. Mean attendance at onsite week-day meals was $92 \%$ at each sodium level for DASH participants and 91\%, 93\%, and 91\% for control participants at higher, intermediate, and lower sodium levels, respectively. Based on daily self-reported checklists that included both weekday and weekend days, DASH and control participants on average were compliant (defined as missing no meals, eating only study foods, and eating no extra nonstudy foods) $91 \%$ and $92 \%$ of the time, respectively. These percentages were virtually identical for all three sodium levels in each diet group. In addition, 24-hour urine collections showed that across all sodium levels participants on the DASH diet had higher mean excretions of potassium ( 3,003 to 3,237 vs 1,560 to $1,599 \mathrm{mg} /$ day [ 77 to 83 vs 40 to 41 $\mathrm{mmol} / \mathrm{day}$ ), phosphorus ( 785 to $831 \mathrm{vs} 645$ to $670 \mathrm{mg} / \mathrm{day}$ [ 253 to 268 vs 208 to $216 \mathrm{mmol} /$ day]), and urea nitrogen ( 11.8 to 12.6 vs 9.6 to $10.1 \mathrm{~g} /$ day [0.42 to 0.45 vs 0.34 to $0.36 \mathrm{~mol} /$ day]) than participants receiving the control diet. The mean sodium levels achieved by the participants based on 24-hour urinary excretions, which reflect a range of energy levels, were similar in each diet group: 3,312,2,461, and 1,495 mg/day $(144,107$, and $65 \mathrm{mmol} /$ day) for the DASH group and 3,266, 2,415, and 1,403 mg/day (142, 105, and $61 \mathrm{mmol} / \mathrm{day})$ for the control group at higher, intermediate, and lower sodium levels, respectively.

\section{Salt and Overall Diet Acceptability by Sodium Level}

Participants in each diet group successfully distinguished between the three different levels of sodium (Table 1). Participants in each diet group consistently gave the highest acceptability ratings to the intermediate sodium level (range in $P$ values for differences between intermediate and either lower or higher sodium levels in all eight possible comparisons: 0.01 to 0.0001$)$. Overall, differences in salt acceptability scores were not dramatic between sodium levels for either diet: approximately one point. There was no difference in salt acceptability between the higher and lower sodium level, except with the DASH diet, where the higher sodium level received a poorer score than the lower sodium level for willingness to continue with this level of saltiness (4.3 vs $4.9, P=0.02$ ). 
For the overall diet, participants in both diet groups gave the highest acceptability scores to the intermediate salt level, although statistical significance was achieved in only three of eight possible comparisons with the intermediate level (intermediate vs lower sodium $P$ values: 0.01 to 0.0004$)$. For liking the overall diet, DASH and control participants gave the next highest acceptable rating to the higher sodium level $(P=0.04$ and 0.02 , respectively, for higher vs lower sodium). There were no significant differences between higher and lower sodium levels for willingness to continue. Differences in overall diet acceptability scores were generally small between sodium levels for both diets: approximately one-half point.

\section{Change in Salt Acceptability with Time}

We found no significant change in acceptability of sodium level with either the DASH or control diet during the 4 weeks that participants were on each of the three sodium levels (data not shown).

\section{Acceptability of DASH Compared with Control Diet}

At all sodium levels, compared with the control diet, participants on the DASH diet liked their overall diet more (by $0.9,0.7$, and 0.8 points for lower, intermediate, and higher sodium levels, respectively, $P<0.05$ to $<0.005$ ), and were more willing to continue that diet (by $0.9,1.1$, and 1.2 points, respectively, $P<0.01$ to $<0.0001$ ). Range in mean ratings (unadjusted for run-in) was 5.6 to 6.6 for the DASH diet and 5.2 to 6.1 for the control diet. Participants on the DASH diet also rated more highly at all sodium levels the components of the DASH diet compared with control diet participants. For fruits and vegetables, mean ratings ranged from 7.3 to 7.4 for the DASH diet and 5.4 to 5.7 for the control diet. For dairy, mean ratings ranged from 6.3 to 6.4 for the DASH diet and 5.3 to 5.5 for the control diet. Specifically, compared with control diet participants and adjusted for run-in, DASH diet participants rated higher: the amount of fruits and vegetables by 2.3, 2.0, and 2.1 points for lower, intermediate, and higher sodium levels (all $P<0.0001$ ); willing to continue that level of fruits and vegetables by $1.9,1.9$, and 2.0 points, respectively (all $P<0.0001$ ); amount of dairy by $1.4,1.4$, and 1.2 points, respectively (all $P<0.0001$ ); and willing to continue that amount of dairy by $1.7,1.4$, and 1.2 points, respectively (all $P \leq 0.0001$ ). Interaction terms of diet with sodium level were not significant.

\section{Results of Subgroup Analyses}

There were no significant differences in ratings between subgroups defined by obesity, age, sex, and hypertension status. There were significant differences in acceptability by race.

\section{Salt Acceptability According to Sodium Levels by Race Subgroups}

Within-race subgroup comparisons showed similar patterns to those reported in Table 1, namely, for both races and both diets, the intermediate salt level was almost always rated higher than either the lower or higher sodium level (significant for 75\% [12 out of 16] of the comparisons, see Table 2, upper half).

African Americans and non-African Americans receiving the DASH diet did not differ in salt acceptability (Table 2, upper half), but there were race differences for the control diet. Among those receiving the control diet, the second most acceptable salt level for African Americans was the higher sodium level, whereas non-African Americans receiving the control diet ranked the lower sodium level as the second most acceptable. Of six possible comparisons, racial differences in salt acceptability ratings (liking and willingness to continue) for the control diet were significant for four comparisons (lower vs intermediate and lower vs higher; average difference among six scores was about one point). Differences between African Americans and non-African Americans in overall diet acceptability ratings 
on the control diet (liking and willingness to continue) were smaller than those for salt acceptability; just two out of six possible between-race subgroup comparisons-lower vs intermediate - attained statistical significance (average difference in scores was about onehalf point).

\section{Acceptability of the DASH Diet and Its Components by Race Subgroups}

At all sodium levels, African Americans and non-African Americans liked the DASH diet to a similar extent (Table 2, lower half). Diet acceptability scores ranged from 5.5 to 6.5 for African Americans and 5.8 to 6.7 for non-African Americans. In contrast, diet acceptability scores on the control diet ranged from 5.8 to 6.8 for African Americans but only 4.0 to 5.0 for non-African Americans (range in $P$ values for between-race differences: 0.03 to $<0.0001$ ). Thus, the higher acceptability of the DASH diet compared with the control diet was seen only in non-African Americans.

Acceptability scores for the number of servings of the key food groups that define the DASH dietary pattern (eg, fruits and vegetables, low-fat dairy products) in both African Americans and non-African Americans were almost always higher on the DASH diet than control diet (significant for more than 75\% [19 out of 24] of the comparisons, see Table 3). Scores were similar between African Americans and non-African Americans receiving the DASH diet at all three sodium levels (about 0.1 point different for fruits and vegetables and about 0.3 point different for dairy servings). Compared with non-African Americans, African Americans were more accepting of and gave higher scores to the number of servings of fruits and vegetables and dairy products provided in the control diet. All 12 between-race comparisons were significant (range in $P$ values: 0.0004 to $<0.0001$ ). Thus, the magnitude of acceptability for the DASH diet features compared with the control diet was greater for nonAfrican Americans than for African Americans.

\section{DISCUSSION}

This study assessed the acceptability of sodium-reduced research diets by participants in the DASH-Sodium trial (14). Participants on both the DASH and control diets gave relatively high acceptability ratings to all levels of sodium, ranging on average from four to seven points. The intermediate level received somewhat higher ratings than either the lower or higher sodium. The DASH diet and its components received higher scores than the control diet at all sodium levels. Overall diet acceptability scores were about $15 \%$ higher for the DASH diet than the control diet, and the key components of the DASH diet (eg, fruits and vegetables and dairy) were rated about $25 \%$ to $30 \%$ higher. Race differences were observed whereby African Americans found the control diet more acceptable than the DASH diet compared with non-African Americans.

In the DASH-Sodium trial, the intermediate sodium level may have provided the best mix of sodium level with flavor and texture enhancement for the foods in the DASH-Sodium research diets, making it the most acceptable sodium level. Particularly striking was the finding that the lower sodium level was at least as acceptable as the higher sodium level in both diets.

It is likely that participants' habituation to high sodium intakes before enrolling in this study - mean urinary sodium excretion during screening was $3,565 \pm 1,725 \mathrm{mg} /$ day $(155 \pm 75$ $\mathrm{mmol} /$ day) $(3,634 \pm 1,725 \mathrm{mg} /$ day $[158 \pm 75 \mathrm{mmol} /$ day $]$ and $3,519 \pm 1,725 \mathrm{mg} /$ day $[153 \pm 75$ $\mathrm{mmol} / \mathrm{day}$ ] for participants subsequently assigned to the DASH or control diet, respectively) vs $3,289 \pm 1,725 \mathrm{mg} /$ day $(143 \pm 75 \mathrm{mmol} /$ day) during the higher sodium level period-tended to cause the lower sodium level to have somewhat lower acceptability ratings than the intermediate level. Similarly, reduced preference for salt occurs when low levels of salt are 
consumed over a period of time $(11,23,26,27)$. It appears that change in salt preference in response to a low-salt diet may take 8 to 12 weeks (23). Thus, 30 days was probably too short a time period to observe a change in salt acceptability in the DASH-Sodium trial.

Constraints on research diets could also affect salt and diet acceptability. For example, the research menus were developed to provide a variety of food tastes and textures that would accommodate a variety of tastes. Consequently, spices were limited in food preparation to promote overall diet acceptability, and the numbers and types of foods, as well as the need for controlled food production procedures in a research setting, reduced the number of recipes and mixed foods provided that otherwise might be used by a free-living population.

The lower sodium level was more acceptable with the DASH than the control diet, perhaps because the DASH diet provided more acceptable flavor and texture combinations than the control diet. Jeffery and colleagues (28) found that participants preferred to reduce sodium intake by eating more foods that are naturally low in sodium, such as fruits and vegetables, instead of using low-sodium processed foods that were considered less palatable. The DASH-Sodium trial included both approaches for reducing sodium. Replacement of highsodium foods with lower-sodium versions may have reduced the palatability of the lowersodium diets, particularly with the control diet, which had fewer servings of fruits and vegetables that are naturally low in sodium than the DASH diet. Nevertheless, differences in scores among the three sodium levels were relatively small. A limitation of this study is that it is not clear how these scores may be related to self-selected and self-prepared foods outside of a research setting.

The finding that the higher sodium level ranked lower in acceptability than the intermediate level was unexpected and, at first glance contradictory to the idea that habituation to higher levels of sodium would increase acceptance of similarly high levels. It is possible that participants, who were chosen for their risk of hypertension, were more prone to give the "right" answer based on heightened awareness of the salt-hypertension relationship. Also, the way the research diets were prepared may have contributed in part to the lower acceptance of the higher sodium levels. In current food processing methods, salt is typically added during food processing to serve as a texture-, color-, and flavor-enhancer. In contrast, in the DASH-Sodium trial, to accurately control sodium levels, weighed salt was added directly to certain foods after preparation or salted broth was given to increase the sodium content of the diets (29). Participants anecdotally reported their food to be "too salty," consistent with the observation that surface-coating foods with salt increases the level of perceived saltiness (30). The high-sodium foods, therefore, may have deviated from expected flavors and textures and may have been perceived saltier than they really were.

Although both DASH and control participants rated the intermediate sodium level the most acceptable, differences in acceptability scores between intermediate and lower sodium levels were small, about one point for salt acceptability and about one-half point for overall diet acceptability on a one- to nine-point scale. The intermediate target sodium level of 2,300 $\mathrm{mg} /$ day $(100 \mathrm{mmol} /$ day $)$ per $2,100 \mathrm{kcal}$ corresponds to the upper limit of sodium intake recommended by several public health organizations $(19,20,31)$. If average sodium intake in the US population is reduced to this level, substantial blood pressure reduction is likely (14). However, the DASH-Sodium trial also showed that blood pressure was reduced twice as much by consuming the lower sodium level $(1,200 \mathrm{mg} /$ day [50 mmol/day] per 2,100 kcal) compared with the intermediate target level of 2,300 mg/day $(100 \mathrm{mmol} /$ day $)$ per $2,100 \mathrm{kcal}$ (14). The US food production system, which makes prepared food convenient and readily available, unduly relies on salt for flavor to enhance consumer acceptability. Some difficulties people have with lowering dietary sodium intake include inconvenience, lack of time to plan for and prepare meals, and low availability of low-sodium foods in grocery 
stores and low-sodium food choices when eating out $(32,33)$. The future challenge is to develop methods and procedures in culinary art and food processing that could lead to greater acceptability of low-sodium diets.

Race was the only demographic characteristic that was associated with differences in sodium and diet acceptability. For sodium level acceptability, African Americans and nonAfrican Americans assigned to the DASH diet rated the higher and lower sodium levels similarly. However, with the control diet, African Americans generally gave the lowest acceptability ratings to the lower sodium level, whereas non-African Americans generally gave the lowest ratings to the higher sodium level. African Americans' greater acceptability than non-African Americans of the higher sodium levels may reflect differences in flavor preferences. Marketing data indicate that African Americans generally prefer spicier foods with a higher salt content $(34,35)$.

For overall diet acceptability, African Americans rated the DASH and control diets similarly, whereas non-African Americans rated the DASH diet more positively than the control diet. However, both African Americans and non-African Americans rated the likableness of the amounts of fruits and vegetables and dairy foods in the DASH diet higher than the amounts of these foods in the control diet. The high acceptability of the DASH diet components among African Americans implies that it is possible to alter diets for African American to include more fruits, vegetables, and low-fat dairy products. The DASH diet would represent an improved eating pattern for African Americans, who tend to eat fewer fruits, vegetables, and dairy foods than the general US population (36-40).

\section{CONCLUSIONS}

This study found that during 30 days of consuming research diets at three levels of sodium, the intermediate sodium level was slightly more acceptable than either the higher or lower level, which generally had similar ratings. Whether or not acceptability was influenced by the sodium levels themselves or by the manner in which the research diets were prepared cannot be determined in this study. Nonetheless, these differences in salt acceptability between sodium levels were small, and the overall acceptability ratings for lower and intermediate sodium levels were relatively high, par ticularly with the DASH diet. We also found the DASH diet more acceptable than the control diet at all sodium levels. We conclude that both the lower sodium level, a level similar to that which is currently recommended as adequate intake and a goal to aim for (41), and the intermediate level, which is the safe upper limit (41), are acceptable to participants with, or at risk for, hypertension.

These results suggest that adults may be amenable to reducing their sodium intake, particularly in the context of a diet rich in fruits and vegetables that is naturally low in sodium, such as the DASH diet. The DASH diet meets the US Dietary Guidelines for Americans and the Institute of Medicine nutrient recommendations $(20,41)$ and is also compatible with some therapeutic diets. As a first step, food and nutrition professionals can emphasize to their patients the goal of 2,300 $\mathrm{mg} / \mathrm{day}(100 \mathrm{mmol} / \mathrm{day})$ sodium, a level that was considered most acceptable in this study. To achieve that goal, food and nutrition professionals can counsel their patients to consume more unprocessed foods and, especially, increase their intake of fruits and vegetables. They should also stress to patients the importance of reading food labels so that lower-sodium versions of foods can be identified and selected. Food and nutrition professionals should inform their patients that preference for salt taste will diminish over time as they begin to eat lower-sodium foods and that they can creatively add nonsodium spices and herbs to foods to provide alternative flavors. Food and nutrition professionals should also support public health approaches such as the effort of 
the American Medical Association Position Statement to reduce the population burden of cardiovascular disease by reducing sodium intake through health policy and public health education $(42,43)$. In addition, food and nutrition professionals, patients, and consumers can raise awareness in their communities of the need for more lower-sodium choices by requesting more low-sodium food choices at their supermarkets, asking for salt-free seasonings at restaurants and fast-food establishments, and buying products with no salt added to give the food industry a message that reduced sodium food products and meals are in demand.

\section{Acknowledgments}

This research was supported by cooperative agreement and other awards from the National Heart, Lung, and Blood Institute, National Institutes of Health, to Pennington Biomedical Research Institute (no. U01-HL57190), Brigham and Women's Hospital (no. U01-HL57173), Duke University (no. U01-HL57114), Johns Hopkins University (nos. U01-HL57139 and K08 HL03857), and Kaiser Permanente Center for Health Research (no. U01-HL57156), and from the General Clinical Research Center Program of the National Center for Research Resources, National Institutes of Health to Brigham and Women's Hospital (no. M01-RR02635) and Johns Hopkins University (no. M01-RR00722).

The authors thank the DASH-Sodium participants, the DASH-Sodium investigators and staff, and the Data and Safety Monitoring Board. The authors also thank Richard Mattes, PhD, MPH, RD, who substantially contributed to the design of the sodium and diet acceptability questionnaire, and Jeffrey Cutler, MD, MPH, whose thoughtful and insightful comments on the manuscript were gratefully appreciated.

\section{References}

1. Cutler JA, Follmann D, Allender PS. Randomized trials of sodium reduction: an overview. Am J Clin Nutr. 1997; 65(suppl):643S-651S. [PubMed: 9022560]

2. He FJ, MacGregor GA. Effect of longer-term modest salt reduction on blood pressure (review). Cochrane Database Syst Rev. 2004; 3:CD004937. [PubMed: 15266549]

3. Vollmer WM, Sacks FM, Ard J, Appel LJ, Bray GA, Simons-Morton DG, Conlin PR, Svetkey LP, Erlinger TP, Moore TJ, Karanja N. Effects of diet and sodium intake on blood pressure: Subgroup analysis of the DASH-sodium trial. Ann Intern Med. 2001; 135:1019-1028. [PubMed: 11747380]

4. Evers SE, Bass M, Donner A, McWhinney IR. Lack of impact of salt restriction advice on hypertensive patients. Prev Med. 1987; 16:213-220. [PubMed: 3588562]

5. Alli C, Avanzini F, Bettelli G, Bonati M, Colombo F, Corso R, Di TM, Gentile MG, Sangalli L, Taioli E. Feasibility of a long-term low-sodium diet in mild hypertension. JAMA. 1992; 6:281-286.

6. Hashimoto J, Imai Y, Minami N, Munakata M, Sakuman H, Sekino H, Imai K, Sasaki S, Yoshinaga $\mathrm{K}$, Abe K. Compliance with long-term dietary salt restriction in hypertensive outpatients. Clin Exp Hypertens. 1994; 16:729-739. [PubMed: 7858556]

7. Korhonen MH, Litmanen H, Rauramaa R, Vaisanen Sb, Niskanen L, Uusitupa M. Adherence to the salt restriction diet among people with mildly elevated blood pressure. Eur J Clin Nutr. 1999; 53:880-885. [PubMed: 10557001]

8. Appel LJ, Champagne CM, Harsha DW, Cooper LS, Obarzanek E, Elmer PJ, Stevens VJ, Vollmer WM, Lin PH, Svetkey LP, Stedman SW, Young DR, Writing Group of the PREMIER

Collaborative Research Group. Effects of comprehensive lifestyle modification on blood pressure control: Main results of the PREMIER clinical trial. JAMA. 2003; 289:2083-2093. [PubMed: 12709466]

9. Kumanyika SK, Hebert PR, Cutler JA, Lasser VI, Sugars CP, Steffen-Batey L, Brewer AA, Cameron M, Shepek LD, Cook NR. Feasibility and efficacy of sodium reduction in the Trials of Hypertension Prevention, Phase I. Trials of Hypertension Prevention Collaborative Research Group. Hypertension. 1993; 22:502-512. [PubMed: 8406655]

10. Kumanyika SK, Cook NR, Cutler JA, Belden 1, Brewer A, Cohen JD, Hebert PR, Lasser VI, Raines J, Raczynski J, Shepek L, Diller L, Whelton PK, Yamamoto M. Sodium reduction for hypertension prevention in overweight adults: further results from the Trials of Hypertension Prevention Phase II. J Hum Hypertens. 2005; 19:33-45. [PubMed: 15372064] 
11. Beauchamp GK, Engelman K. High salt intake. Sensory and behavioral factors. Hypertension. 1991; 17:I176-I181. [PubMed: 1987000]

12. Havas S, Roccella EJ, Lenfant C. Reducing the public health burden from elevated blood pressure levels in the United States by lowering intake of dietary sodium. Am J Public Health. 2004; 94:1922. [PubMed: 14713688]

13. Svetkey LP, Sacks FM, Obarzanek E, Vollmer WM, Appel LJ, Lin PH, Karanja NM, Harsha DW, Bray GA, Aickin M, Proschan MA, Windhauser MM, Swain JF, McCarron PB, Rhodes DG, Laws RL. The DASH Diet, Sodium Intake and Blood Pressure Trial (DASH-sodium): Rationale and design. DASH-Sodium Collaborative Research Group. J Am Diet Assoc. 1999; 99(suppl):S96S104. [PubMed: 10450301]

14. Sacks FM, Svetkey LP, Vollmer WM, Appel LJ, Bray GA, Harsha D, Obarzanek E, Conlin PR, Miller ER, Simons-Morton DG, Karanja N, Lin PH, Aickin M, Most-Windhauser MM, Moore TJ, Proschan MA, Cutler JA. Effects on blood pressure of reduced dietary sodium and the Dietary Approaches to Stop Hypertension (DASH) diet. N Engl J Med. 2001; 344:3-10. [PubMed: 11136953]

15. Karanja NM, Obarzanek E, Lin PH, McCullough ML, Phillips KM, Swain JF, Champagne CM, Hoben KP. Descriptive characteristics of the dietary patterns used in the Dietary Approaches to Stop Hypertension Trial. DASH Collaborative Research Group. J Am Diet Assoc. 1999; 99(suppl):S19-S27. [PubMed: 10450290]

16. Appel LJ, Moore TJ, Obarzanek E, Vollmer WM, Svetkey LP, Sacks FM, Bray GA, Vogt TM, Cutler JA, Windhauser MM, Lin PH, Karanja N. A clinical trial of the effects of dietary patterns on blood pressure. DASH Collaborative Research Group. N Engl J Med. 1997; 336:1117-1124. [PubMed: 9099655]

17. Denke, MA.; Obarzanek, E. Well-Controlled Diet Studies in Humans: A Practical Guide to Design and Management. The American Dietetic Association; Chicago, IL: 1999.

18. Lin PH, Aickin M, Champagne C, Craddick S, Sacks FM, McCarron P, Most-Windhauser MM, Rukenbrod F, Haworth L. Food group sources of nutrients in the dietary patterns of the DASHSodium trial. J Am Diet Assoc. 2003; 103:488-496. [PubMed: 12669013]

19. Chobanian AV, Bakris GL, Black HR, Cushman WC, Green LA, Izzo JL Jr, Jones DW, Materson BJ, Oparil S, Wright JT Jr, Roccella EJ. Seventh report of the Joint National Committee on Prevention, Detection, Evaluation, and Treatment of High Blood Pressure. Hypertension. 2003; 42:1206-1252. [PubMed: 14656957]

20. US Department of Health and Human Services, US Dept of Agriculture. [Accessed June 21, 2007] Dietary Guidelines for Americans. 2005. Available at: http://www.health.gov/dietaryguidelines/dga2005/document/.

21. Intersalt Cooperative Research Group. Intersalt: an international study of electrolyte excretion and blood pressure. Results for 24 hour urinary sodium and potassium excretion. BMJ. 1988; 297:319328. [PubMed: 3416162]

22. Funk KL, Elmer PJ, Stevens VJ, Harsha DW, Craddick SR, Lin PH, Young DR, Champagne CM, Brantley PJ, McCarron PB, Simons-Morton DG, Appel LJ. PREMIER-A trial of lifestyle interventions for blood pressure control: Intervention design and rationale. Health Promot Pract. June 27.2006

23. Mattes RD. The taste for salt in humans. Am J Clin Nutr. 1997; 65(suppl):692S-697S. [PubMed: 9022567]

24. DiNicolantonio R, Teow BH, Morgan TO. Sodium detection threshold and preference for sodium chloride in humans on high and low sodium diets. Clin Exp Pharmacol Physiol. 1984; 11:335-338. [PubMed: 6518662]

25. Liang KY, Zeger SL. Longitudinal data analyses using generalized linear models. Biometrika. 1989; 73:13-22.

26. Bertino M, Beauchamp GK, Engelman K. Long-term reduction in dietary sodium alters the taste of salt. Am J Clin Nutr. 1982; 36:1134-1144. [PubMed: 7148734]

27. Blais CA, Pangborn RM, Borhani NO, Ferrell MF, Prineas RJ, Laing B. Effect of dietary sodium restriction on taste responses to sodium chloride: A longitudinal study. Am J Clin Nutr. 1986; 44:232-243. [PubMed: 3728360] 
28. Jeffery RW, Pirie PL, Elmer PJ, Bjornson-Benson WM, Mullenbach VA, Kurth CL, Johnson SL. Low-sodium, high-potassium diet: feasibility and acceptability in a normotensive population. Am J Public Health. 1984; 74:492-494. [PubMed: 6711725]

29. Most MM, Craddick S, Crawford S, Redican S, Rhodes D, Rukenbrod F, Laws R. Dietary quality assurance processes of the DASH-Sodium controlled diet study. J Am Diet Assoc. 2003; 103:1339-1346. [PubMed: 14520254]

30. Shepherd R, Farleigh CA, Wharf SG. Limited compensation by table salt for reduced salt within a meal. Appetite. 1989; 13:193-200. [PubMed: 2596842]

31. Lichtenstein AH, Appel LJ, Brands M, Carnethon M, Daniels S, Franch HA, Franklin B, KrisEtherton P, Harris WS, Howard B, Karanja N, Lefevre M, Rudel L, Sacks F, Van HL, Winston M, Wylie-Rosett J. Diet and lifestyle recommendations revision 2006: A scientific statement from the American Heart Association Nutrition Committee. Circulation. 2006; 114:82-96. [PubMed: 16785338]

32. Jeffery RW, French SA, Schmid TL. Attributions for dietary failures: Problems reported by participants in the Hypertension Prevention Trial. Health Psychol. 1990; 9:315-329. [PubMed: 2187695]

33. Hooper L, Bartlett C, Davey SG, Ebrahim S. Systematic review of long term effects of advice to reduce dietary salt in adults. BMJ. 2002; 325:628-637. [PubMed: 12242173]

34. Sills-Levy E. US food trends leading to the year 2000. Food Technol. 1989; 43:128-132.

35. Oregon State University Food Resource. [Accessed June 25, 2007] Targeting the black American market. Available at: http://food oregonstate edu/kelsey/tr_black html.

36. US Department of Agriculture, Agricultural Research Service. [Accessed June 24, 2007] Data Tables: Food and Nutrient Intakes by Individuals in the United States, by Race, 1994-96. Table Set 11. Available at: http://www.ars.usda.gov/SP2UserFiles/Place/12355000/pdf/Race.PDF.

37. Campbell MK, Demark-Wahnefried W, Symons M, Kalsbeek WD, Dodds J, Cowan A, Jackson B, Motsinger B, Hoben K, Lashley J, Demissie S, McClelland JW. Fruit and vegetable consumption and prevention of cancer: The Black Churches United for Better Health project. Am J Public Health. 1999; 89:1390-1396. [PubMed: 10474558]

38. Devine CM, Wolfe WS, Frongillo EA Jr, Bisogni CA. Life-course events and experiences: Association with fruit and vegetable consumption in three ethnic groups. J Am Diet Assoc. 1999; 99:309-314. [PubMed: 10076582]

39. Karanja NM, McCullough ML, Kumanyika SK, Pedula KL, Windhauser MM, Obarzanek E, Lin PH, Champagne CM, Swain JF. Pre-enrollment diets of Dietary Approaches to Stop Hypertension trial participants. DASH Collaborative Research Group. J Am Diet Assoc. 1999; 99(suppl):S28S34. [PubMed: 10450291]

40. Resnicow K, Jackson A, Wang T, De AK, McCarty F, Dudley WN, Baranowski T. A motivational interviewing intervention to increase fruit and vegetable intake through black churches: Results of the Eat for Life trial. Am J Public Health. 2001; 91:1686-1693. [PubMed: 11574336]

41. Appel, LJ.; Baker, DH.; Bar-Or, O.; Minaker, KL.; Morris, RC.; Resnick, LM.; Sawka, MN.; Volpe, SL.; Weinberger, MH.; Whelton, PK. Dietary Reference Intakes for Water, Potassium, Sodium, Chloride, and Sulfate. The National Academies Press; Washington, DC: 2005.

42. American Medical Association. [Accessed June 24, 2007] Report 10 of the Council on Science and Health: Promotion of healthy lifestyles I: Reducing the population burden of cardiovascular disease by reducing sodium intake. Available at: http://www.ama-assn.org/ama/pub/category/16413.html.

43. Appel LJ. Salt reduction in the United States. BMJ. 2006; 333:561-562. [PubMed: 16973990] 
1. Rate how salty you thought the diet was ${ }^{a}$

2. Rate how well you liked the overall saltiness of the $\operatorname{diet}^{b}$

3. Rate your willingness to continue eating this level of saltiness ${ }^{c}$

4. Rate how much you liked the amount of fruits and vegetables in this $\operatorname{diet}^{\mathrm{b}}$

5. Rate your willingness to continue eating this level of fruit and vegetable ${ }^{\mathrm{c}}$

6. Rate how much you liked the amount of dairy products in $\operatorname{diet}^{\mathrm{b}}$

7. Rate your willingness to continue eating this level of dairy products $^{c}$

8. Rate how much you liked the diet overall ${ }^{b}$

9. Rate your willingness to continue this type of $\operatorname{diet}^{\mathrm{C}}$

$\mathrm{a}_{1}=$ not at all salty; 4 and $5=$ moderately salty; $9=$ extremely salty.

b1 $1=$ disliked extremely; 4 and $5=$ neither liked nor disliked; $9=$ liked extremely.

${ }^{c} 1=$ not at all willing; 4 and $5=$ unsure; $9=$ extremely willing.

Figure.

List of questions asked on the diet acceptability questionnaire. A 9-point scale was used to elicit responses. 


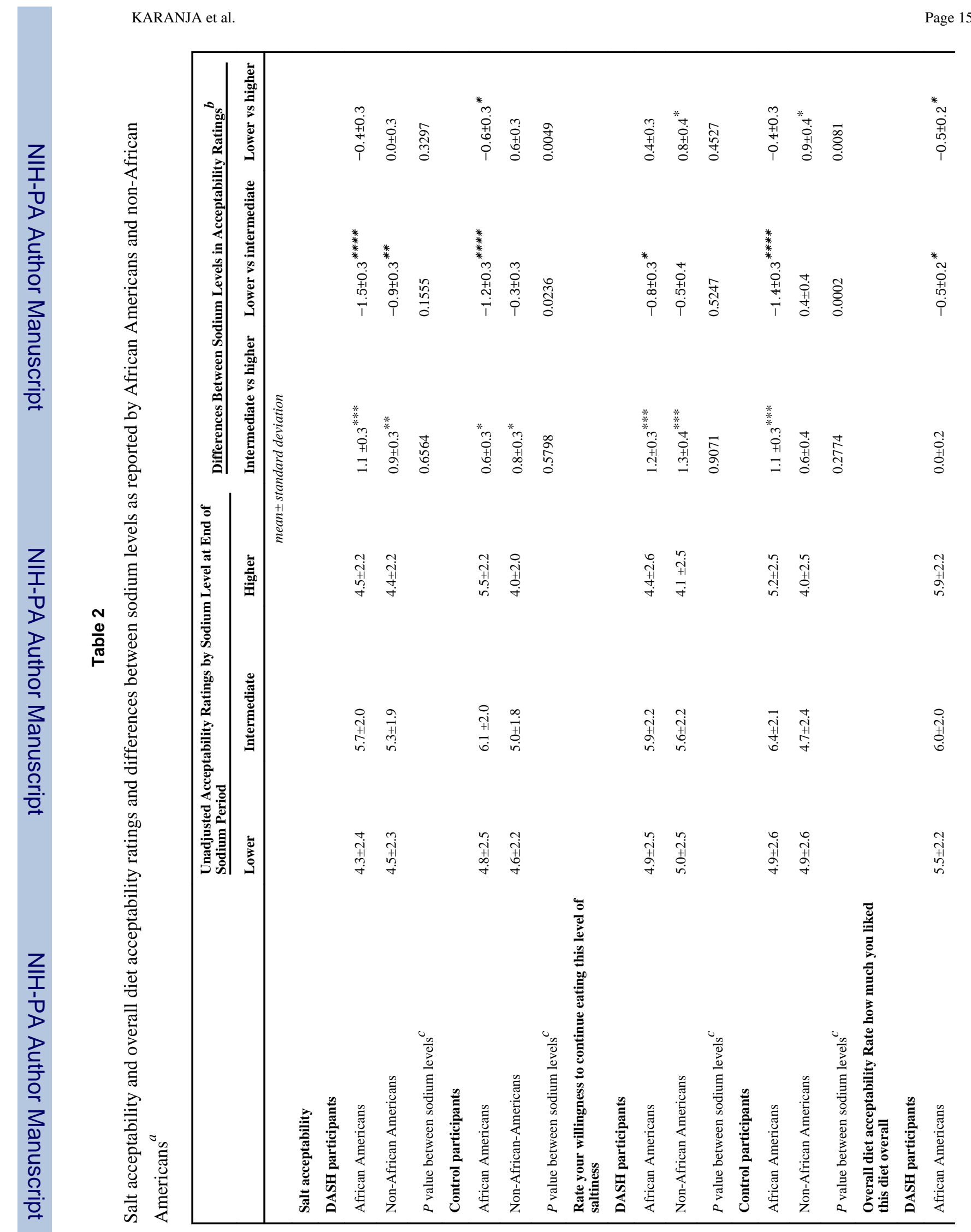

J Am Diet Assoc. Author manuscript; available in PMC 2011 November 17. 


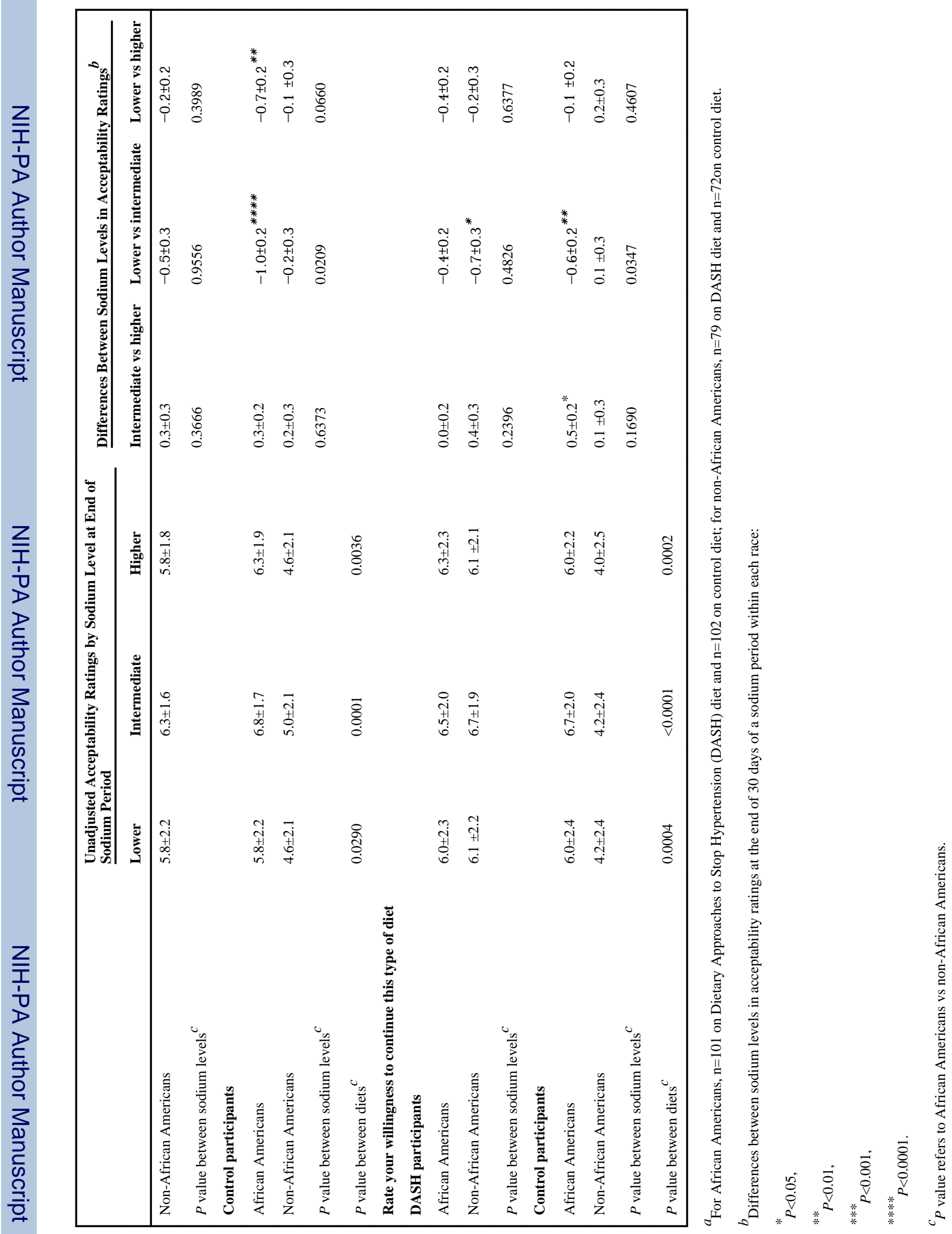




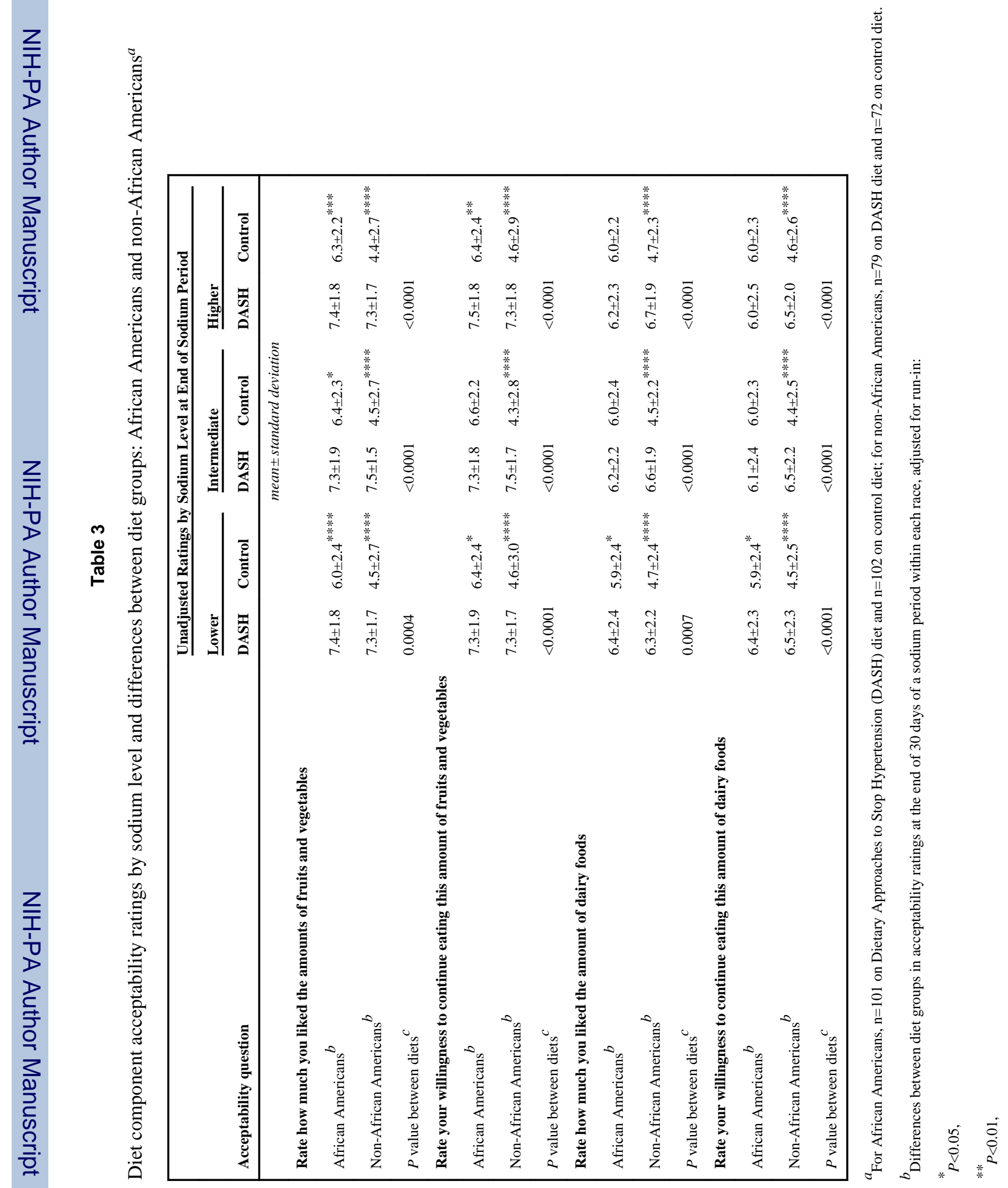


